\title{
THE TECHNOLOGY READINESS OR SOCIAL PRESENCE, WHICH ONE COULD EXPLAIN THE TECHNOLOGY ACCEPTANCE BETTER? AN INVESTIGATION ON VIRTUAL COMMUNITIES
}

\author{
Said Jubran \\ Faculty of Economics and Business \\ Universitas Gadjah Mada \\ (saidjubran@gmail.com)

\section{Sumiyana} \\ Faculty of Economics and Business \\ Universitas Gadjah Mada \\ (sumiyana@ugm.ac.id)
}

\begin{abstract}
Internet technology has accelerated the development of communities from face-to-face into computer-mediated communications. Individuals who joined the virtual communities contributed greatly to building their knowledge by sharing their experiences. This study investigates the individuals' knowledge sharing intentions using two approaches for the research model. The first approach is adopted from Hung \& Cheng's (2013) model that incorporates technology readiness, compatibility and acceptance. The second approach is a new model built specifically for this study which combines the social presence and compatibility into the technology acceptance. Furthermore, this study compared both models to identify their ability to explain the individuals' knowledge sharing intentions.

This study's results show that the first model is not better than the second. In the first model, the technology readiness, as represented only by the innovative, is the only one having a positive effect on the technology acceptance. Meanwhile, the three other constructs, i.e. optimism, discomfort, and insecurity are not. In the second model, the social presence and compatibility that are integrated into the Technology Acceptance Model could actually positively affect the technology acceptance.

In the technology readiness model, the ease of the technology is not the indicator which assesses the usefulness of the technology. Meanwhile, in the social presence model, the ease of use affects the usefulness of the technology. Furthermore, both in the technology readiness and social presence models, the perceived usefulness and ease of use affect the knowledge sharing intentions. The study finds that the social presence is able to explain the knowledge sharing intentions better than the technology readiness does. It implies practically that virtual community providers should make individuals be more active in their virtual communities. Then, the providers could facilitate the improvement of the individuals' cognitive capabilities and competencies with their high motivation for knowledge sharing.
\end{abstract}

Keywords: technology readiness, social presence, communications medium, compatibility, virtual community, online learning

\section{INTRODUCTION}

Humans are social beings who learn and work in groups (Read \& Miller, 1995). Internet technology connects internet users with information. The Internet, as a social medium, (Baym et al., 2004; Walther \& Parks, 2002) is used to communicate with friends, relatives, co-workers, and even for forming new relationships (Madden \& Lenhart, 2006). The growth of internet technology brought new innovations, of which one 
was the formation of virtual communities for online learning. These virtual communities make knowledge sharing among the participants possible. They continue to grow in accordance with the organizations vision and mission, educational institutions, and governments' incentives to obtain or distribute knowledge through the internet.

Previous studies identified several problems related to the contribution of knowledge. From the behavioral point of view, Davenport \& Prusak (1998) explained that knowledge sharing was an "unnatural" characteristic because people tended to believe that their knowledge was more valuable than the other participants'. Furthermore, individuals do not give away their knowledge and were skeptical of the quality of the knowledge of others. However, there has been a shift in this behavior. The phenomena that occured at this time were that the individuals tended to override any unnatural characteristics. The individuals were willing to give their knowledge to other individuals within their virtual community.

Hung \& Cheng (2013) investigated the behavior of individuals' knowledge sharing intentions of a new technology in virtual communities using the concept of the Technology Readiness Index (Parasuraman, 2000), compatibility (Rodgers, 2003), and the Technology Acceptance Model (Davis, 1989). They mainly measured individuals' perceptions to receive or otherwise reject the use of new technology. Hung \& Cheng (2003) found that high levels of individual optimism and innovativeness affect the acceptance of technology, as well as the perception of the usefulness of it, and the ease of use of the technology. Both optimism and innovativeness motivate individuals' knowledge sharing intentions. Furthermore, the low levels of insecurity and discomfort do not describe the individuals' technology acceptance, and the individuals' perception of compatibility does not affect the knowledge sharing intention.

This study becomes very important since it provides an alternative model to the concept proposed by Hung \& Cheng (2003). From our point of view, the technology acceptance does not depend greatly on the individuals' perspective; instead the technology acceptance is supported by the individuals' presence in the social community. The perceived suitability of the information technology also stimulates the individuals to attend and use it. It plainly implies that the technology acceptance is not affected by the technology readiness index, but it is affected by the social presence concept. In other words, we designed the new alternative model because of the individuals' motivation to attend the social media networks. Clearly, it is not because of the individuals' traits and experiences. Furthermore, we presumed that the technology acceptance was more stimulated by the individuals' outward looking perspective rather than inward looking. At least, this study will further develop the technology acceptance by adding our proposed presumptions.

A virtual community is a technological medium where individuals from various places build knowledge and meet the individuals' need for information through the process of communication and interaction. The social presence is a central concept in online learning (Lowenthal, 2009). It is used as a key component in the theoretical framework of learning networks (Benbunan, 2005), distance education (Vrasidas \& Glass, 2002), student satisfaction (Gunawardena, 1995; Gunawardena \& Zittle, 1997; Richardson \& Swan, 2003), development of a community of learners (Rourke et al., 2001; Rovai, 2002) and perceived learning (Richardson \& Swan, 2003). Therefore, the theory of social presence is reliable regarding the online learning environment. Short et al. (1976) indicated that, the greater the individuals' perception was of a personal, sensitive, warm, and sociable communications medium, the greater the social presence that would be created. As a result, the interaction and communication among users improved and the online learning process further demonstrated its quality.

This study assumes that the users are active in social networking and their intention is to influence others in a positive manner through knowledge sharing and discovery (Lau, 2012). We raised this assumption because this study 
ignored the individuals' powerlessness to use microcomputers as a tool of the social media networks. This assumption is relevant to the concept of social technologies which was built for the functions of socialization and personal entertainment, and can be applied to the learning environment. On the other hand, virtual communities are the product of online social networks, and this is one of the features of social technology in which there are social networking ties. Furthermore, these social network ties, as a form of relationship bonding between two or more parties, based on their partnership, are formed within the social networks (Haythornthwaite, 1998).

Based on earlier discussions, the research question is "Which one better explains the individuals' knowledge sharing intentions: the technology readiness or the social presence?" This research provides an insight into the understanding of the individuals' motivation to share knowledge. This study compares the two research models that trigger an individuals' involvement in the knowledge sharing intention. First, we adopted the research model of Hung \& Cheng (2013) that integrated the technology readiness, compatibility, and acceptance (Fig. 1). Second, we developed a new research model by inducing the social presence and compatibility into the Technology Acceptance Model (Fig. 2).

This section presents the introduction, then the rest of the discussions are as follows. The second section presents the theoretical basis and hypotheses development for the knowledge sharing intentions, in the perspective of the two models, i.e. the technology readiness and social presence. This study further analyzes and compares the two models of technology acceptance. The last section is the study's conclusions.

\section{THEORETICAL BACKGROUND HYPOTHESIS DEVELOPMENT}

AND

\section{Virtual Community and Knowledge Sharing}

The virtual community is a part of cyberspace-based information technology that is used by people to communicate and interact, so they could learn, contribute and build knowledge
(Hsu et al., 2007). This virtual community also brings social values and expectations (Burnett \& Dickey, 2003). The internet technology facilitates the interaction and exchange of information or knowledge among the users in a virtual space.

Knowledge sharing motivates the use of a virtual community (Wasko \& Faraj, 2000). The exchange of knowledge is important for improving learning performance. It is the behavior of conveyance or delivery, in which a person gains knowledge from others (Ryu et al, 2003). Meanwhile, Lee (2001) argued that knowledge sharing was an activity in which an individual, group, or organization provided or disseminated knowledge to other parties or people. Holthouse (1998) stated that knowledge was a flow concept, which connected the knowledge owners with the recipients. Bock et al. (2005) argued that knowledge sharing was behavior which provided and delivered knowledge. Wijnhoven (1998) stated that knowledge sharing was the process of knowledge transfer through the medium of information, and the knowledge receivers integrated the knowledge they received into new knowledge. Related to perceived learning, Senge (1997) stated that the objective of knowledge sharing was to improve the ability of individuals' or organizations' knowledge, as well as to help and not just to give or to get something from the others. Furthermore, an individual interacts with social networks because they want to influence their hegemony to be received by others.

\section{Model Development}

Technology Readiness Index-Compatibility-TAM (TRI-C-TAM)

Hung \& Cheng (2003) induce the Technology Readiness Index (TRI) into the Technology Acceptance Model (TAM). They argued that the technology acceptance was determined by the individuals' factors, based on various arguments. The different views of the individuals always become the determinant factor of the new information technology that is usually used to sell products or services (Agarwal \& Prasad, 1999; Garbarino \& Strahilevitz, 2004; Venkatesh et al., 2003). The frustration individuals experienced 
usually came from the use of the new information technology. Rodgers (2003) stated that the individuals' traits and experiences affected the user's acceleration to accept the new technology and then influence the distribution of information or knowledge. Parasuraman \& Colby (1998) explained the concept of TRI that evaluated extensively the individuals' attitude toward the acceptance and use of new technology. The TRI refers to the influences of personality traits when the individuals wish to fulfill their goals at their work, especially when the individuals adapt to the new technology.

The high compatibility tends to motivate the individuals' willingness to adopt the information technology (Moore \& Banbasat, 1991). The concept of compatibility explains that the ideas of new technological innovations will be adopted easily when they are consistent with the existing values, past experiences, and requirements of potential users (Rodgers, 2003). Previous research showed that the perfect compatibility was very useful in the activity of knowledge sharing at work, as it could give birth to new ideas by the employees (Hislop, 2003; Lai \& Chen, 2011; Lin et al., 2009; Lin \& Lee, 2006).

\section{Social Presence-Compatibility-TAM (SP-C-TAM)}

This study presents an alternative to the model proposed by Hung \& Cheng (2003) which induced the Technology Readiness Index. It induces the social presence under the arguments that follow. Senge (1997) suggested that the objective of knowledge sharing was to increase the individuals' ability or skill or the organizations' actions. It meant that the individuals did not only acquire or deliver their knowledge, but they were ready to assist other individuals. Therefore, the individuals perform an online learning process. The social presence becomes the central concept in online learning (Lowenthal, 2009). The individuals gather, interact, and communicate via a communications medium as a learning process to acquire knowledge from the features of the new technological innovations.
The concepts of compatibility explain that the ideas of new technological innovations will be adopted easily when they are consistent with the existing values, past experiences, and requirements of potential users (Rodgers, 2003). The high compatibility of technology will bring a high level of technological adoption by the individuals. Its social presence and compatibility are two external concepts which can affect the individuals' acceptance of technology in virtual communities (Lee et al., 2003).

\section{Hypotheses Development}

The Technology Acceptance Model (TAM) developed by Davis et al. (1989) was based on the Theory of Reasoned Action (TRA) model (Ajzen \& Fishbein, 1980) but with two additional main constructs, namely the perceived usefulness and perceived ease of use. This TAM model argues that the individuals' acceptance of information technology systems is determined by the two constructs. The perceived usefulness explains the users' perception of the new technology by improving the performance of duties as well as future career prospects. Davis et al. (1989) indicated that behavioral intention was influenced directly by the perceived usefulness and perceived ease of use (Chismar \& WileyPatton, 2003; Hong et al., 2011; Lin, 2011; Taylor \& Todd, 1995; Venkatesh et al., 2003; Wu \& Chen, 2005; Szajna, 1996).

This study argues that individuals usually support others to do knowledge sharing. Alternatively, individuals take these benefits since they need less effort to conduct their work and achieve their performance. Therefore, we established the following hypothesis.

H1: The individuals' level of the perceived usefulness of a technology within virtual communities has a positive relationship on the individuals' knowledge sharing intention.

The perceived ease of use can increase the intention to use online learning through the perceived usefulness (Liu et al., 2010; Sánchez \& Hueros, 2010; Sun \& Zhang, 2003). Our study argues that, despite an individuals' slight effort, they receive great benefits, in comparison with 
their minimal efforts. Therefore, we constructed the following hypothesis.

H2: The individuals' level of the perceived ease of use of technology within a virtual community has a positive correlation on the individuals' knowledge sharing intention.

If the new technology can be easily understood, implemented and can provide a good experience to individuals, then they will feel that the new technology can be beneficial to them, and be used in carrying out their activities. It also means that they exert less effort to do what they need to do. Therefore, we developed a hypothesis as follows.

H3: The individuals' level of the perceived ease of use of technology within a virtual community has a positive association on the individuals' perceived usefulness of it.

\section{Compatibility}

Compatibility is the external factor of TAM which could strengthen the knowledge sharing intentions. Rodgers (2003) argued that compatibility was the level of the individuals' perception of an innovation which was consistent with the existing values, past experiences, and potential requirements for its use. Compatibility is the most important attribute of innovations that may affect the adoption of technology by an individual. Our study argues that individuals who find technology which meets with their expectations tend to build or to improve their knowledge in a virtual community. It means that they feel that their cognitive fit is high. We summarize this into the hypothesis statement below.

H4: The individuals' level of compatibility with a technology within a virtual community has a positive relationship on the individuals' intention to share knowledge.

\section{Technology Readiness}

Parasuraman (2000) developed the Technology Readiness Index (TRI) to measure individuals' technology readiness. The technology readiness is the willingness and use of new technol- ogy by individuals to achieve their goals in daily life. The TRI contains four dimensions of the individuals' beliefs toward the technology that can influence the individuals' technology readiness. Two dimensions are positive and serve as contributors, i.e. optimism and innovativeness. The other two are negative and work as inhibitors of individuals to adopt the new technology, namely discomfort and insecurity. Tsikriktsis (2004) stated that the users with different levels of technology readiness will have differences in their use of, and intentions to use, the information technology.

Optimism is the degree to which individuals believe that the new technology will bring benefits and is controllable, flexible, and efficient in their daily lives. Because of individuals' optimism, they tend to use new technology (Scheier \& Carver, 1987) and form a more positive attitude towards new technologies (Loyd \& Gressard, 1984; Munger \& Loyd, 1989). Liljander et al. (2006) measured the technology readiness of self-service technology and found that users with high optimism had high technology acceptance. Therefore, we establish the following hypotheses.

H5a: The individuals' high level of optimism within a virtual community will improve the individuals' perceived usefulness of a technology

H5b: The individuals' high level of optimism within a virtual community will improve the individuals' perceived ease of use of a technology

H5c: The individuals' high level of optimism within a virtual community will improve the individuals' perceived compatibility of a technology

Innovation triggers individuals to be the first users of new technology. They do not consider the new technology as complex or difficult to understand (Karahanna et al., 1999). They are enthusiastic about the presence of new technology and try to use it based on professional knowledge (Midgley \& Dowling, 1978). Citrin et al. (2000) stated that users with a particular specialization that had a high level of innova- 
tiveness tended to increase network utilization. Our study argues that users are not afraid to utilize new technology. They feel that they could redo or reconduct their work without much effort. Therefore, we construct the following hypotheses.

H6a: The individuals' high level of innovativeness within a virtual community will improve the individuals' perceived usefulness of a technology

H6b: The individuals' high level of innovativeness within a virtual community will improve the individuals' perceived ease of use of a technology

H6c: The individuals' high level of innovativeness within a virtual community will improve the individuals' perceived compatibility of a technology

The individuals who felt uncomfortable with new technology also felt unable to adopt that technology, and felt uneasy because they could not control the technology, as well as anxiety about being controlled by the technology (Dabholkar, 1996; Norman, 1998). Therefore, individuals with a high level of discomfort perceive a new technology as complex and subsequently this affects the level of the individual's technology acceptance. This research states that discomfort is contrary to innovativeness. Therefore, we establish the following hypotheses.

H7a: The individuals' high level of discomfort within a virtual community will reduce the individuals' perceived usefulness of a technology

H7b: The individuals' high level of discomfort within a virtual community will reduce the individuals' perceived ease of use of a technology

H7c: The individuals' high level of discomfort within a virtual community will reduce the individuals' perceived compatibility of a technology

Individuals with insecurity consider new technology is not safe to be used because it can- not guarantee the confidentiality of the information of the users. Individuals who are skeptical about the safety of the new technology are not willing to use it. Chen et al. (2002) examined consumers' behavior in an online store, and found that the insecurity of the networks could affect the individuals' intention to buy from the online store. Our study believes that individuals' insecurity in using information technology is equivalent to the individuals' discomfort. They are reluctant to use the new technology because they would have to spend additional effort to maintain their performance. In addition, they also need to protect their privacy if/when they use internet systems. This we turned into the following hypotheses.

H8a: The individuals' high level of insecurity within a virtual community will reduce the individuals' perceived usefulness of a technology

H8b: The individuals' high level of insecurity within a virtual community will reduce the individuals' perceived ease of use of a technology

H8c: The individuals' high level of insecurity within a virtual community will reduce the individuals' perceived compatibility of a technology

\section{Social Presence}

Short et al. (1976) build the social presence theory that is often used to explain the influence of communications mediums (Lowenthal, 2009). Short et al. (1976) suggested that the social presence was the quality of the presence among members within the communications medium. This theory states that the physical and technological characteristics of the communications medium are the objective qualities of the communications medium that will determine the level of social presence. Furthermore, this theory as the alternative attributes of the communication medium in determining how people interact and communicate. 


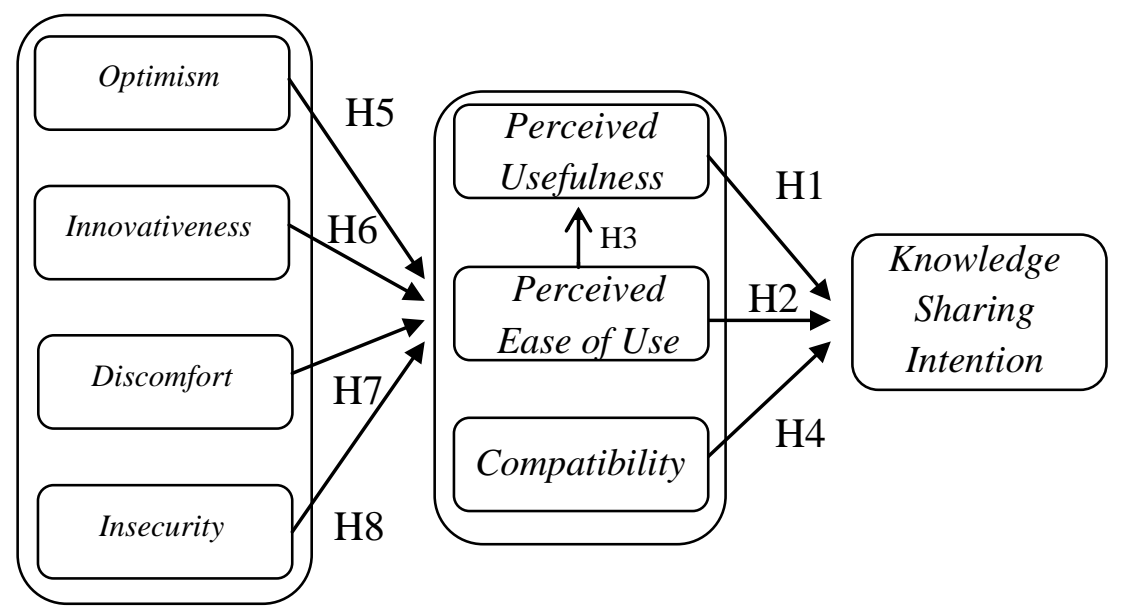

Figure 1 Research Model 1-Technology Readiness Index-Compatibility-TAM (TRI-C-TAM) (Hung \& Cheng, 2013).

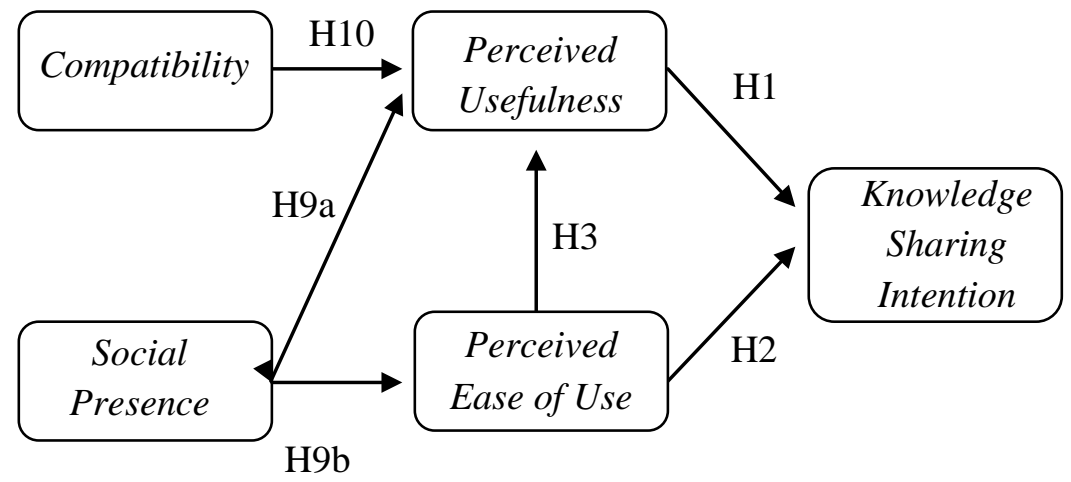

Figure 2 Research Model 2-Social Presence-Compatibility-TAM (SP-C-TAM).

Several previous studies indicated that social presence may affect learning networks (Benbunan, 2005), distance education (Vrasidas \& Glass, 2002), users satisfaction (Gunawardena, 1995; Gunawardena \& Zittle, 1997; Richardson \& Swan, 2003), the development of a community of learners (Rourke et al., 2001; Rovai, 2002) and perceived learning (Richardson \& Swan, 2003). Social presence directly relates to the interaction of learner-tolearner. It means that learners usually need to interact with other learners, so that they will be considered as "being there" and "being real" (Moore \& Kearsley, 2005).

Short et al. (1976) built the commonly used construct measurement of social presence. This measurement used four dimensions; personalimpersonal, sensitive-insensitive, warm-cold, sociable-unsociable and took seven bipolar semantic scales to measure the subjective levels of social presence. The higher the individuals' perception of the personal, sensitive, warmth, and sociable dimensions, the higher the social presence. Gefen \& Straub (1997) investigated the influence of gender on the TAM model by adding the construct of social presence and information richness. Their results showed that women had a higher perceived usefulness, whereas men were more concerned with the perceived ease of use.

We argue that more presence gives more benefits to individuals because less effort is needed. Individuals will get benefits which far outweigh their efforts, because they are in the virtual communities. Therefore, this became the following hypotheses.

$\mathrm{H}_{9 \mathrm{a}}$ : The individuals' higher perception of social presence within a virtual community will increase the individual's perceived useful- 
ness of a technology.

$\mathrm{H}_{9 \mathrm{~b}}$ : The individuals' higher perception of social presence within a virtual community will increase the individual's perceived ease of use of a technology.

Also on perceived compatibility, Chau \& Hu (2004) examined the technology acceptance of telemedicine by the physicians in health services in Hong Kong. The research results showed that the construct of compatibility does not directly influence the behavioral intention, but directly affects the perceived usefulness. Moore \& Benbasat (1991) examined the use of the Personal Work Station (PWS) and found that its compatibility affected the perceived usefulness. This suggests that the individuals' perceived compatibility determines the level of their interest in using the information technology.

We recall our argument in H4. Individuals' cognitive fit improves their perceived benefits. It means that they would be addicted to reusing the information technology. So, we raise the following hypothesis.

$\mathrm{H}_{10}$ : The individuals' level of compatibility to a technology within a virtual community has a positive correlation on the individuals' perceived usefulness of the technology.

\section{RESEARCH METHODOLOGY}

\section{Sample and Variable Definition}

The population in this study comprised of the users of virtual communities. This study selected the sample by using a snowball sampling method. Although this sampling method has the disadvantage of not being able to control the respondents, we chose this method because of its speed and cost efficiency for data collection. We collected the data through surveying techniques. We build web-based questionnaires to collect our data. The completion of the questionnaire was voluntary. This study was designed to have no forced or mandatory demands, to hopefully ensure that the respondents' responses to the questionnaire were objective. We adopted the measurements of the research constructs from the previous studies shown in Table 1. The constructs consisted of the technology readiness, social presence, compatibility, and technology acceptance.

This study conducted data validity and reliability tests. Subsequently, we employed a Structural Equation Model (SEM) to test the goodness of fit of the research models. It used some criteria to measure the suitability of the observation, or actual input (covariance or correlation matrix) with the predictions proposed by the model. The Criteria for Goodness of Fit consisted of $\chi^{2}$ divided by the Degree of Freedom (CMIN/DF), Root Mean Square Error of Approximation (RMSEA), Goodness of Fit Index (GFI), Adjusted Goodness of Fit Index (AGFI), Tucker Lewis Index (TLI), and Comparative Fit Index (CFI).

\section{RESULTS}

\section{Demographics and Descriptive Statistics}

This study obtained a valid sample of 306 respondents from the web-based questionnaires. They actively used social media networks as specified by the research's sampling methods. It means that they do not have problems utilising social media systems. Table 2 illustrates the respondents' demographic characteristics. The respondents were mainly in the age range of 1625 years old ( $188=61.4 \%$ of the respondents). From the characteristics of their occupations, 153 (50\%) of the respondents were students. From the type of virtual community they used, Facebook users dominated with 116 (37.9\%) respondents and the least were bloggers with only $1(0.3 \%)$ respondent. Most respondents, (146 $=47.7 \%)$, do their knowledge sharing once every 3 days, and the highest number of respondents, $(115=37.5 \%)$ of respondents, were knowledgeable about mobile phone technology.

Table 3 shows the data obtained from the respondents. All research constructs showed good results, as can be seen by the values for the standard deviation that were smaller than the average value (mean) and all of the data were distributed normally. 
Table 1. The Operational Definition

\begin{tabular}{|c|c|c|}
\hline Constructs & Measurement & References \\
\hline Optimism & $\begin{array}{l}\text { Controllability, flexibility, and efficiency in life due to } \\
\text { technology; } 5 \text { items, } 5 \text { Likert scales }\end{array}$ & Parasuraman (2000) \\
\hline Innovativeness & $\begin{array}{l}\text { Tendency to figure out new technology, enjoy the challenge, have } \\
\text { fewer problems than other people; } 5 \text { items, } 5 \text { Likert scales }\end{array}$ & \\
\hline Discomfort & $\begin{array}{l}\text { Not designed by ordinary people, uncomfortable, embarrassing } \\
\text { when you have trouble, fail at the worst possible time; } 5 \text { items, } 5 \\
\text { Likert scales }\end{array}$ & \\
\hline Insecurity & $\begin{array}{l}\text { Unsecure, information will be seen by other people; } 5 \text { items, } 5 \\
\text { Likert scales }\end{array}$ & \\
\hline Personal & Intimacy, familiarity, harmony; 7 scales semantic bipolar. & Short et al. (1989) \\
\hline Sensitive & Enthusiasm, excitement; 7 scales semantic bipolar. & \\
\hline Warm & Responsiveness; 7 scales semantic bipolar. & \\
\hline Sociable & Friendliness, complacency; 7 scales semantic bipolar. & \\
\hline $\begin{array}{l}\text { Perceived } \\
\text { compatibility }\end{array}$ & $\begin{array}{l}\text { Compatibility with the technology, adaptability, fit their style; } 5 \\
\text { items, } 5 \text { Likert scales }\end{array}$ & $\begin{array}{l}\text { Lin, (2011); Gerrard \& } \\
\text { Cunningham, (2003) }\end{array}$ \\
\hline $\begin{array}{l}\text { Perceived } \\
\text { usefulness }\end{array}$ & $\begin{array}{l}\text { Helpfulness, performances' improvement, effectiveness, useful, } \\
\text { increase productivity; } 6 \text { items, } 5 \text { Likert scales }\end{array}$ & $\begin{array}{l}\text { Moore \& Benbasat } \\
\text { (1991) }\end{array}$ \\
\hline $\begin{array}{l}\text { Perceived ease of } \\
\text { use }\end{array}$ & Easy to use, flexibility, understandability; 5 items, 5 Likert scales & $\begin{array}{l}\text { Davis et al. (1989); } \\
\text { Chau, (1996) }\end{array}$ \\
\hline $\begin{array}{l}\text { Knowledge } \\
\text { sharing intention }\end{array}$ & $\begin{array}{l}\text { Likely to use in the future, acceptability, seek of technology; } 4 \\
\text { items, } 5 \text { Likert scales }\end{array}$ & \\
\hline
\end{tabular}

Table 2. The Demographic Characteristics of Respondents

\begin{tabular}{llrr}
\hline Variable & Charateristics & Frequency & Percentage (\%) \\
\hline Gender & Male & 154 & 50.3 \\
\multirow{4}{*}{ Age } & Female & 152 & 49.7 \\
& Under 16 & 7 & 2.3 \\
& $16-25$ & 188 & 61.4 \\
& $26-35$ & 92 & 30.0 \\
Occupation & $36-45$ & 13 & 4.2 \\
& Above 45 & 6 & 1.9 \\
& State Employee & 30 & 9.8 \\
The Type of Virtual & Private Employee & 70 & 22.8 \\
Communities & Student & 153 & 50.0 \\
& Entrepreneur & 53 & 17.4 \\
& Indowebster & 12 & 3.9 \\
Knowledge Sharing Frequency & Facebook & 116 & 37.9 \\
& Twitter & 71 & 23.2 \\
& Kaskus & 75 & 24.5 \\
& Others (LikedIn, Skype, Google+, etc.) & 32 & 10.4 \\
& Once a week & 146 & 47.7 \\
The Scope of Technology & Once a month & 64 & 20.9 \\
& Others & 72 & 23.5 \\
& Computer & 24 & 7.9 \\
& PC Tablet & 107 & 34.9 \\
& Mobile phone & 62 & 21.1 \\
& Others & 115 & 37.5 \\
\hline
\end{tabular}

Source: Summary of Statistical Output 
Table 3. Descriptive Statistics

\begin{tabular}{ccccccc}
\hline Variable & Min & Max & Mean & Median & Modus & Std. Deviation \\
\hline SP & 2.00 & 7.00 & 5.0433 & 5.00 & 5.00 & 1.18303 \\
OPT & 2.00 & 5.00 & 4.0425 & 4.00 & 4.00 & .63050 \\
INN & 1.80 & 5.00 & 3.5092 & 3.00 & 3.00 & .55702 \\
DIS & 1.00 & 5.00 & 3.4118 & 3.00 & 3.00 & .68568 \\
INS & 1.00 & 5.00 & 3.2464 & 3.00 & 3.00 & .76192 \\
C & 2.20 & 5.00 & 3.9980 & 4.00 & 4.00 & .62505 \\
PU & 2.17 & 5.00 & 4.1531 & 4.00 & 4.00 & .63209 \\
PEU & 2.00 & 5.00 & 3.9373 & 4.00 & 4.00 & .67400 \\
KSI & 2.25 & 5.00 & 4.1234 & 4.00 & 4.00 & .61977 \\
\hline
\end{tabular}

Note: $\mathrm{SP}=$ Social Presence, OPT=Optimism, INN=Innovativeness, DIS=Discomfort, INS=Insecurity, $\mathrm{C}=$ Compatibility, $\mathrm{PU}=$ Perceived Usefulness, $\mathrm{PEU}=$ Perceived Ease of Use, KSI=Knowledge Sharing Intention; N: 306

Source: Summary of Statistical Output

\section{Constructs Validity and Reliability Analysis}

The research considered that all of the instruments were valid because the value of the Confirmatory Factor Analysis (CFA) was above 0.50 . We also considered that all of the instruments were reliable because their Composite Reliability (CR) value was well above or almost close to 0.70 . The measurement items which had a value for their factor loading of under 0.50 were excluded from the examination.

The construct of social presence had four valid and reliable measurement items. A number of items of the construct of technology readiness did not meet the value for their factor loading, and thus were excluded from the examination. This study finally concluded that all of the constructs of compatibility, perceived usefulness, and perceived ease of use were highly valid and reliable. One measurement item was removed from the constructs of knowledge sharing intention because it did not meet the determined criteria of its factor loading. The results of the construct of the validity and reliability analysis are presented as follows (Table 4).

The GFI and AGFI values did not meet the criterion that was set at above 0.90 , but the values were closer to the specified criteria. The TLI, CFI, and RMSEA for research models 1 and 2 all met the fitness criteria. The chi-square value of research model 2 was lower than that of research model 1.

\section{Analysis and Discussion}

Table 6 presents the results of the hypotheses' examination. Table 6 shows that, concerning research model 1 , the perceived usefulness affected the knowledge sharing intentions (H1: $\beta_{1}=0.43, \mathrm{p}<0.01$ ), as well as the perceived ease of use $\left(\mathrm{H} 2: \beta_{2}=0.26, \mathrm{p}<0.01\right)$. In research model 2 , the perceived usefulness $(\mathrm{H} 1$ : $\left.\beta_{1}=0.54, \mathrm{p}<0.01\right)$ and ease of use $\left(\mathrm{H} 2: \beta_{2}=\right.$ $0.26, \mathrm{p}<0.01$ ) influenced the knowledge sharing intention. Therefore, $\mathrm{H} 1$ and $\mathrm{H} 2$ in both research models were supported positively and significantly, and supported previous studies (Chismar \& Wiley-Patton, 2003; Hong et al., 2011; Lin, 2011; Venkatesh et al., 2003; Wu \& Chen, 2005; Szajna, 1994). Technologies that provide benefits in the form of improvements to the effectiveness and efficiency of task execution, improvements to performance, productivity improvements, and ease of use can increase the individuals' level of the technology acceptance. It means subsequently that a high level of acceptance of the technology can increase the individuals' knowledge sharing intentions in virtual communities.

Hypothesis H3 of research model 1 stated that the perceived ease of use affects the perceived usefulness, was not supported (H3: $\beta_{3}$ $=0.08, \mathrm{p}>0.1)$. In contrast, the $\mathrm{H} 3$ of research model 2 was supported positively and significantly $\left(\mathrm{H} 2: \beta_{2}=0.33, \mathrm{p}<0.01\right)$ and supported previous studies (Liu et al., 2010; 
Sanchez \& Hueros, 2010; Sun \& Zhang, 2003). In the technology readiness model, individuals usually perceive technology as mandatory, so they do not consider the ease of use and the technology's efficiency as important attributes when assessing the usefulness of new technology. In the social presence model, individuals perceive technology to be a voluntary use thing. In that situation, the ease of use and the technology's efficiency are not considered as important properties in assessing the usefulness of new technologies. Individuals are usually motivated to use the technology regardless of its additional efforts or costs.

Table 4. The Results of the Constructs of the Validity and Reliability Analysis

\begin{tabular}{|c|c|c|c|c|}
\hline Construct & $\begin{array}{l}\text { N. of } \\
\text { Items }\end{array}$ & $\begin{array}{l}\text { Factor } \\
\text { Loading }\end{array}$ & $\begin{array}{c}\text { Confirmatory } \\
\text { Factor Analysis }\end{array}$ & $\begin{array}{l}\text { Composite } \\
\text { Reliability }\end{array}$ \\
\hline Social Presence & 4 & $\begin{array}{l}0.81 \\
0.83 \\
0.80 \\
0.85\end{array}$ & 0.82 & 0.82 \\
\hline Optimism & 5 & $\begin{array}{l}0.80 \\
0.90 \\
0.71 \\
0.54 \\
0.51\end{array}$ & 0.69 & 0.93 \\
\hline Innovativeness & 2 & $\begin{array}{l}0.90 \\
0.59\end{array}$ & 0.74 & 0.81 \\
\hline Discomfort & 3 & $\begin{array}{l}0.53 \\
0.87 \\
0.50\end{array}$ & 0.63 & 0.67 \\
\hline Insecurity & 4 & $\begin{array}{l}0.52 \\
0.64 \\
0.88 \\
0.85\end{array}$ & 0.72 & 0.82 \\
\hline Perceived Usefulness & 6 & $\begin{array}{l}0.80 \\
0.82 \\
0.86 \\
0.86 \\
0.85 \\
0.72\end{array}$ & 0.82 & 0.96 \\
\hline Perceived Ease of use & 5 & $\begin{array}{l}0.77 \\
0.79 \\
0.80 \\
0.82 \\
0.82\end{array}$ & 0.80 & 0.93 \\
\hline Perceived Compatibility & 5 & $\begin{array}{l}0.68 \\
0.78 \\
0.80 \\
0.55 \\
0.67\end{array}$ & 0.70 & 0.88 \\
\hline $\begin{array}{l}\text { Knowledge Sharing } \\
\text { Intention }\end{array}$ & 3 & $\begin{array}{l}0.66 \\
0.94 \\
0.82\end{array}$ & 0.81 & 0.91 \\
\hline
\end{tabular}


Table 5. Goodness of Fit Model

\begin{tabular}{lccc}
\hline \multicolumn{1}{c}{ Criteria } & Cut-off Standards & $\begin{array}{c}\text { Research Model 1* } \\
\text { TR-C-TAM }\end{array}$ & $\begin{array}{c}\text { Research Model 2 } \\
\text { SP-C-TAM }\end{array}$ \\
\hline Chi-Square & Limit close to small & 962.147 & 408.776 \\
$P$ & $\geq 0.05$ & 0.000 & 0.000 \\
CMIN/DF & $\leq 2.00$ & 2.096 & 1.937 \\
RMSEA & $\leq 0.08$ & 0.060 & 0.055 \\
GFI & $\geq 0.90$ & 0.836 & 0.892 \\
AGFI & $\geq 0.90$ & 0.799 & 0.859 \\
TLI & $\geq 0.95$ & 0.906 & 0.950 \\
CFI & $\geq 0.95$ & 0.906 & 0.950 \\
\hline
\end{tabular}

Notes: *Adopted from Hung \& Cheng (2013); TRI-C-TAM: Technology Readiness Concept Technology Acceptance Model; SP-C-TAM: Social Presence Concept - Technology Acceptance Model.

Source: Summary of Statistical Output

Table 6. Research Models’ Causality Examinations

\begin{tabular}{|c|c|c|c|c|c|}
\hline \multirow[t]{2}{*}{ Hypotheses } & \multirow[t]{2}{*}{ Causality Relationship } & \multicolumn{2}{|c|}{$\begin{array}{l}\text { Research Model } 1 \\
\text { TRI-C-TAM }\end{array}$} & \multicolumn{2}{|c|}{$\begin{array}{c}\text { Research Model } 2 \\
\text { SP-C-TAM }\end{array}$} \\
\hline & & Coefficient & C.R & Coefficient & C.R \\
\hline H1 (+) & $P U \rightarrow K S I$ & $0.43^{* * *}$ & 6.100 & $0.54 * * *$ & 7.446 \\
\hline $\mathrm{H} 2(+)$ & $P E U \rightarrow K S I$ & $0.26^{* * *}$ & 4.238 & $0.26^{* * *}$ & 3.981 \\
\hline H3 (+) & $P E U \rightarrow P U$ & 0.08 & 1.019 & $0.33^{* * *}$ & 4.115 \\
\hline $\mathrm{H} 4(+)$ & $C \rightarrow K S I$ & $0.12^{* * *}$ & 1.958 & - & - \\
\hline H5a (+) & $O P T \rightarrow P U$ & $0.25^{* * *}$ & 3.318 & - & - \\
\hline $\mathrm{H} 5 \mathrm{~b}(+)$ & $O P T \rightarrow P E U$ & 0.16 & 1.927 & - & - \\
\hline $\mathrm{H} 5 \mathrm{c}(+)$ & $O P T \rightarrow C$ & 0.06 & 0.703 & - & - \\
\hline H6a (+) & $I N N \rightarrow P U$ & $0.63^{* * *}$ & 5.578 & - & - \\
\hline $\mathrm{H} 6 \mathrm{~b}(+)$ & $I N N \rightarrow P E U$ & $0.66^{* * *}$ & -2.442 & - & - \\
\hline H6c (+) & $I N N \rightarrow C$ & $0.73^{* * *}$ & 6.631 & - & - \\
\hline H7a (-) & $D I S \rightarrow P U$ & 0.04 & 0.430 & - & - \\
\hline H7b (-) & $D I S \rightarrow P E U$ & $-0.30 * * *$ & -2.442 & - & - \\
\hline H7c (-) & $D I S \rightarrow C$ & -0.08 & -0.678 & - & - \\
\hline H8a (-) & $I N S \rightarrow P U$ & -0.08 & -0.897 & - & - \\
\hline H8b (-) & $I N S \rightarrow P E U$ & $0.28 * * *$ & 2.589 & - & - \\
\hline H8c (-) & $I N S \rightarrow C$ & 0.01 & 0.119 & - & - \\
\hline H9a $(+)$ & $S P \rightarrow P U$ & & & $0.32 * * *$ & 6.147 \\
\hline H9b $(+)$ & $S P \rightarrow P E U$ & - & - & $0.41^{* * *}$ & 6.379 \\
\hline $\mathrm{H} 10(+)$ & $C \rightarrow P U$ & - & - & $0.37 * * *$ & 4.116 \\
\hline
\end{tabular}

Note: $\mathrm{SP}=$ Social Presence, OPT=Optimism, INN=Innovativeness, DIS=Discomfort, INS= Insecurity,

$\mathrm{C}=$ Compatibility, $\mathrm{PU}=$ Perceived Usefulness, $\mathrm{PEU}=$ Perceived Ease of Use, KSI= Knowledge Sharing Intention

Source: Summary of Statistical Output

Hypothesis $\mathrm{H} 4$ of research model 1 which stated that the compatibility affected the knowledge sharing intentions, was supported ( $\mathrm{H} 4: \beta_{4}$ $=0.12, \mathrm{p}<0.05)$. In research model $2, \mathrm{H} 10$ which stated that the compatibility affected the perceived usefulness was also supported positively and significantly $\left(\mathrm{H} 10: \beta_{10}=0.37, \mathrm{p}<\right.$
0.01) and supported previous research (Chau \& $\mathrm{Hu}, 2004$; Moore \& Benbasat, 1991). These findings indicate that the compatibility affects the knowledge sharing intentions both directly and indirectly. Individuals, whose performance have increased or have had good experiences in their work with the help of technological com- 
patibility and controllability, have opportunities to share their experiences with other individuals in a virtual community.

The social presence affects the individuals' perceived usefulness (H9a: $\beta_{9 a}=0.32, p<0.01$ ) and ease of use (H9b: $\beta_{9 b}=0.41, p<0.01$ ). Thus H9 in research model 2 was supported. The high quality of communication mediums will result in quality interactions and communication among the individuals within the virtual communities so that the knowledge, in the form of an understanding of the benefits and ease of the technology, will increase. This will further encourage the individuals' intentions to share knowledge about the new technology. Social presence is directly related to the interaction of learner-tolearner (Moore \& Kearsley, 2005). Individuals in virtual communities could interact and communicate when they are in a virtual community. In other words, they are in a form of social presence, so that they can build knowledge sharing together. The individuals also established perceived learning (Richardson \& Swan, 2003), and learning networks (Benbunan, 2005), in which they share and educate each other with what they know about the technology through the virtual communities. The individuals' specific knowledge of technologies will increase, both in terms of the benefits, usability, and ease. They can assess a technology based on information they have obtained. Therefore, this study supports the previous research by Gefen \& Straub (1997), which stated that the social presence affected the perceived usefulness and perceived ease of use.

The positive dimension of technology readiness and optimism, correlates positively and significantly with its perceived usefulness (H5a: $\beta_{5 \mathrm{a}}$ $=0.25, \mathrm{p}<0.01)$, but does not have a positive and significant association with the perceived ease of use (H5b: $\beta_{5 b}=0.16, p>0.1$ ) and compatibility (H5c: $\left.\beta_{5 c}=0.06, p>0.1\right)$. It shows that the individuals have a conviction that the new technology won't bring benefits into their daily lives. It is possible that individual traits did not accelerate their acceptance because they were already familiar with the technology.

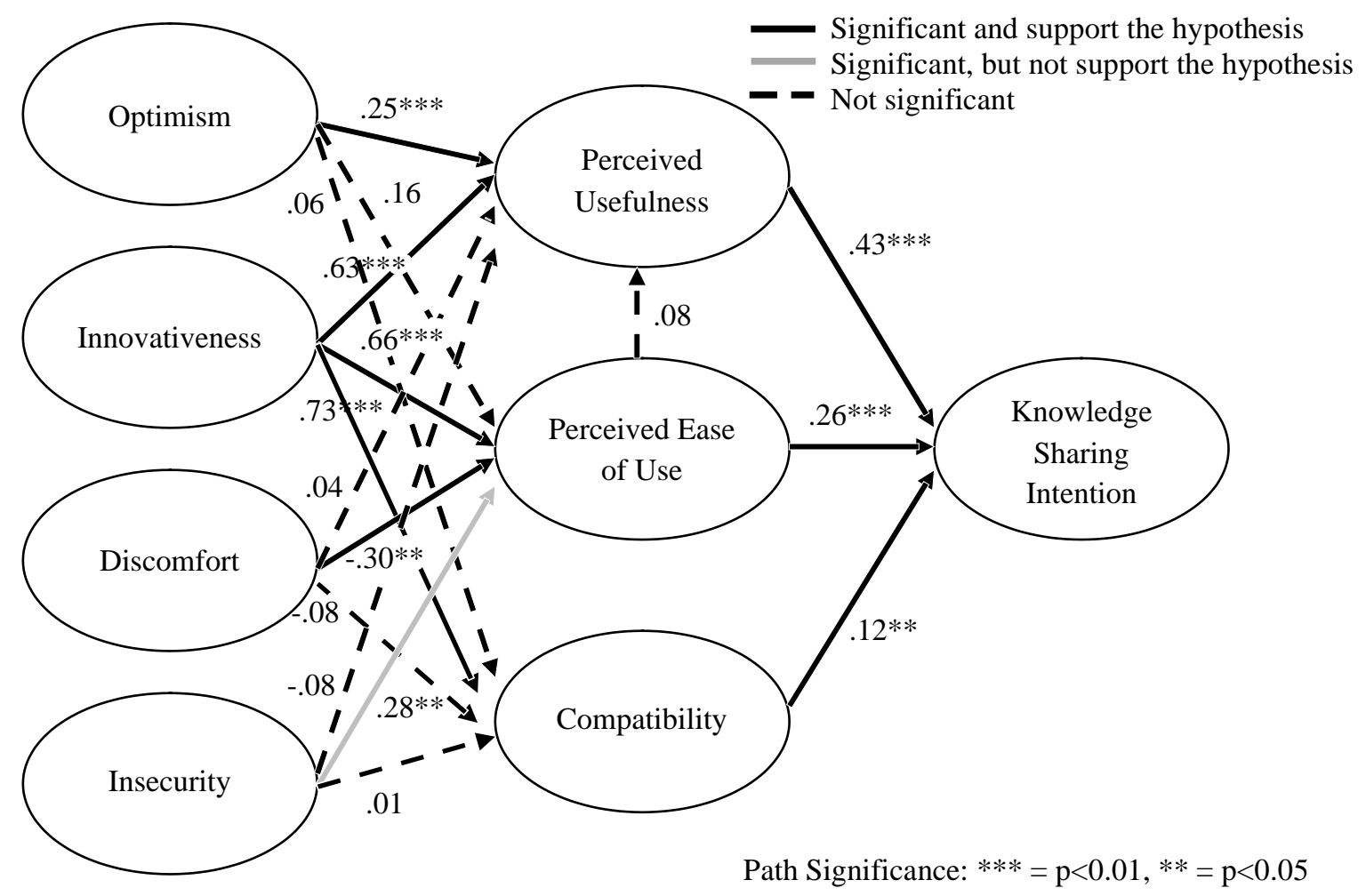

Figure 3. The Results of Research Model 1 (TRI-C-TAM) 


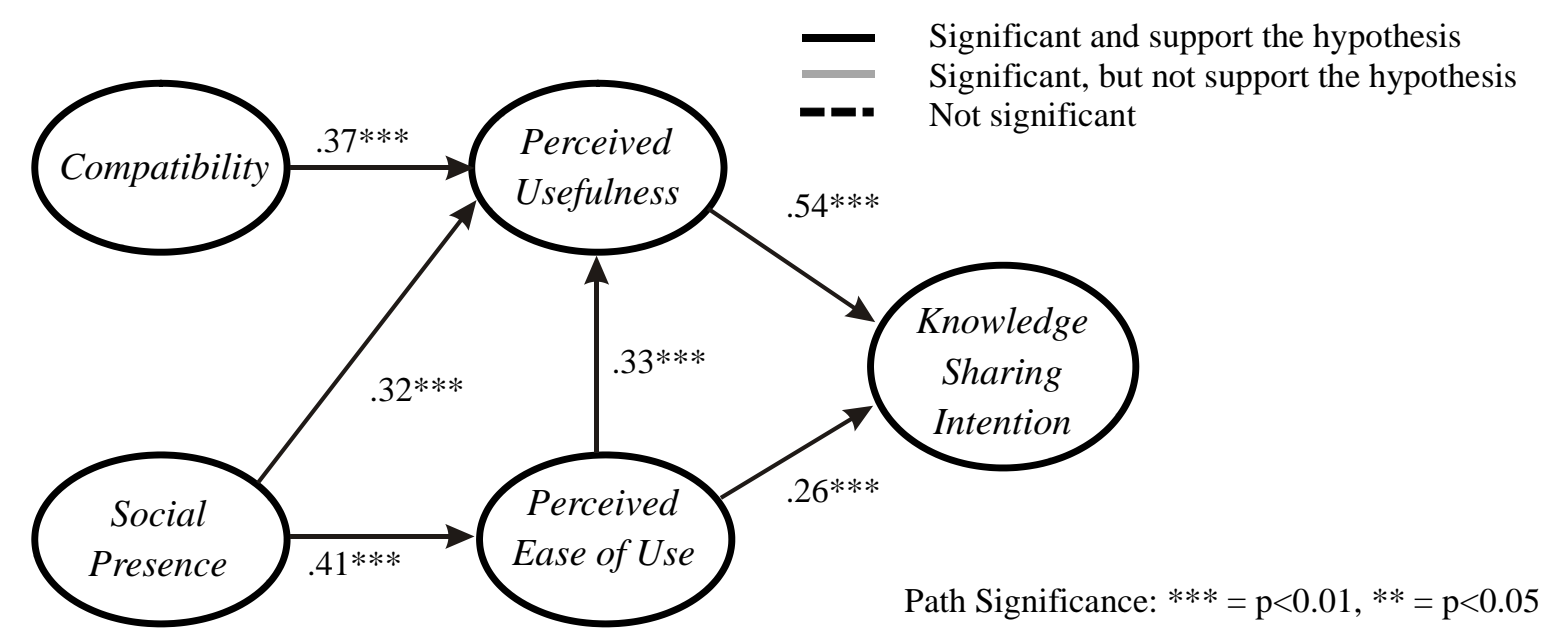

Figure 4. The Results of Research Model 2 (SP-C-TAM)

New technology with the latest features can be beneficial for completing a job effectively and efficiently. However, individuals have positive beliefs that this is only limited to the benefits of the technology, but are not entirely optimistic about the ease and comfort of the technology. It takes more effort and learning to encourage the use of new technology with new/different features.

Innovativeness has a positive and significant relationship on the perceived usefulness (H6a: $\left.\beta_{6 \mathrm{a}}=0.63, \mathrm{p}<0.01\right)$, ease of use (H6b: $\beta_{6 \mathrm{~b}}=$ 0.66, $\mathrm{p}<0.01$ ), and compatibility (H6c: $\beta_{6 \mathrm{c}}=$ 0.73 , p < 0.01) so H6 was supported. These findings indicate that an innovative and creative individual rarely has difficulty in adapting to new technology and can quickly assess the new technology. Individuals with a high level of innovativeness are enthusiastic about the new technology, so that they use and build the knowledge related to the technology.

The negative dimension of technology readiness, discomfort, correlates positively and significantly with the perceived ease of use (H7b: $\left.\beta_{7 \mathrm{~b}}=-0.30, \mathrm{p}<0.05\right)$, so H7b was supported. Anxiety, ignorance and the inability of individuals to control the technology, does not rule out the possibility of individuals utilising technology in their daily lives. However, the discomfort did not affect the perceived usefulness (H7a: $\beta_{7 \mathrm{a}}=$ 0.04, $\mathrm{p}>0.05$ ), and compatibility (H7c: $\beta_{7 \mathrm{c}}=$ $0.28, \mathrm{p}>0.05$ ). Individuals sometimes will not adapt to new technology because of the risks its use brings, such as the risk of being spied on by certain parties, or health and safety risks. Therefore, the individual does not feel at ease because they need to add more effort to minimize the risk.

The high level of insecurity did not affect the perceived usefulness (H8a: $\beta_{8 \mathrm{a}}=-0.08, \mathrm{p}>0.05$ ) and compatibility (H8c: $\beta_{8 c}=0.01, p>0.05$ ). However, it had a significant and positive influence on the perceived ease of use, though it does not have the direction coefficient as expected (H8b: $\beta_{8 \mathrm{~b}}=0.28, \mathrm{p}<0.05$ ), so H8 was not supported. The perception of insecurity did not affect the technology acceptance. The individuals assume that the new technology includes better security for its users. Technology with a high level of security convinces people of the benefits and convenience of its use in daily lives.

\section{Research Findings: Comparison Analysis}

Based on the results and findings of this research, research model 2 (SP-C-TAM) is better than research model 1 (TRI-C- TAM). Thus, social presence is one important concept to motivate the technology acceptance and the individuals' knowledge sharing intentions. Interaction, communication, learning, and the formation of social relationships influence and determine the individuals' knowledge sharing intentions. 
Studies of TAM show that high levels of technology acceptance affect the knowledge sharing intention. Individuals who are members of a virtual community are motivated to acquire knowledge about new technologies. The results of this study suggest that individuals with high levels of social presence do perceive technology acceptance in terms of its usability and ease of use. Conversely, individuals with high levels of technology readiness do not perceive technology acceptance from its ease of use, because their use of technology is mandatory. Therefore, this studies contribution to the literature is that social presence becomes the main (primary) alternative when investigating the individuals' knowledge sharing intentions within organizations or virtual communities.

The individuals' knowledge sharing intentions are formed when the individuals' perception of social presence is high. This study provides a practical contribution to the academics that use virtual community-based online learning, for them to pay more attention to the aspect of the quality of the individuals' presence. The quality of the individuals' presence determines the quality of online learning, particularly the knowledge sharing intentions. The practitioners, especially the developers of virtual communities, need to pay more attention to the quality of the communications medium. The individuals' perceived social presence depends on the quality of the communications medium on offer. For the general public, virtual communities offer benefits in the form of vast varieties of knowledge within the scope of a particular area. To advance individuals' knowledge, the quality of social presence in a virtual community is an important stage in comprehensively building their knowledge. This has the same meaning as the shifting model of the individuals' tacit knowledge into a group or organization with explicit knowledge.

\section{CONCLUSIONS AND RECOMMENDATIONS}

This study focused on the comparison of two research models, namely research model 1 and model 2. Model 1 induces the Technology Readiness Index, Compatibility, and Technology
Acceptance Model (TRI-C-TAM). Meanwhile research model 2 incorporated Social Presence, Compatibility, and Technology Acceptance Model (SP-C-TAM). We compared those models to analyze the relationship between each construct within the models with the individuals' knowledge sharing intention within virtual communities, where the people are the users of technology.

The results of research model 1 showed that seven hypotheses were not supported significantly and one of those hypotheses lay in the hypothesis of the Technology Acceptance Model. Positive perceptions of the TRI, such as optimism, affect positively and significantly the perceived usefulness. The innovativeness affects positively and significantly the technology acceptance and compatibility. High levels of innovativeness show good adaptability by the individuals to the new technology. Negative perceptions of the TRI such as discomfort only affect positively and significantly the perceived ease of use, while the insecurity had a significant relationship with the perceived ease of use, but the direction of its coefficients did not support the hypothesis.

We conclude that the perception of technology readiness does not fully explain the individuals' technology acceptance within virtual communities. Thus, the individuals' tendency to knowledge sharing intentions is low. From the theoretical perspective, individuals' knowledge sharing intentions are only marginally explained by the technology readiness.

The results of research model 2 showed that all hypotheses were supported positively and significantly. These results signify social presence as the most important concept to accelerate the technology acceptance and knowledge sharing intentions. The individuals interact and communicate, and also build social relationships with other individuals by forming a perceived learning group (Richardson \& Swan, 2003), in which they can obtain or provide information to the others. It also means that all the individuals already possess the required skills and abilities to use the technology. In other words, the technology is easily understood by all individuals. 
Therefore, we conclude that individuals' knowledge sharing intentions are perfectly explained by social presence.

The TRI concept focuses only on the individual, i.e. what is the perception of the individual, when confronted with a technology, without being influenced by the people around him. Meanwhile, the concept of social presence is that individuals interact and communicate with other individuals via their communications medium. Within the scope of a virtual community, research model 2 can better explain the knowledge sharing intentions in online virtual communities. It implies that information system providers should make individuals be more active in the virtual communities. The providers should have some policies to encourage individuals to be active in their virtual communities.

The limited time was the main constraint in this study. Future studies are expected to continue the research into the phases of actual behavior, which in the context of this research would be the knowledge sharing behavior. Many other factors can strengthen the relationship between the variables in this study, so further research could add to these factors. Further research could also re-examine the research model of a virtual community to follow the level of social presence, because different communication mediums leads to different perceptions of social presence.

\section{REFERENCES}

Agarwal, R., and Prasad, J., 1999. “Are Individual Differences Germane to The Acceptance of New Information Technologies?” Decision Sciences, 30(2), 361-391.

Ajzen, I., and Fishbein, M., 1980. "Understanding Attitude and Predicting Social Behavior,” Englewood Cliff, NJ: prentice Hall.

Baym, N.K., Zhang, Y.B., and Lin, M.C., 2004. "Social Interaction Across Media: Interpersonal Communication on the Internet, Telephone, and Face-To-Face.” New Media and Society, 6(3), doi:10.1177/ 1461444804041438.
Benbunan-Fich, R., Hiltz, S.R., and Harasim, L., 2005. "The Online Interaction Learning Model: An Integrated Theoretical Framework for Learning Networks.” In S. R. Hiltz and R. Goldman (Eds.), Learning together online: Researchon asynchronous learning Networks (pp. 19-37). Mahwah, NJ: Lawrence Erlbaum Associates.

Bock, G.W., Zmud, R.W., and Kim, Y.G., 2005. "Behavioral Intention Formation in Knowledge Sharing: Examining the Roles of Extrinsic Motivators, Social-Psychology Forces, and Organizational Climate.” MIS Quarterly, 29(1), 87-111.

Burnett, G. and Dickey, M.H., 2003. "Inscription and Interpretation of Text: A Cultural Hermeneutic Examination of virtual community.” Information Research, 9(1).

Chau, P.Y.K., 1996. "An Empirical Assessment Of A Modified Technology Acceptance Model.” Journal of Management Information System, (13), pp.185-204.

Chau, P.Y.K., and Hu, P.J.H., 2004. “Technology Implementation For Telemedicine Programs: Lessons from Experiences in Hong Kong," Communications of the ACM, 47(2), 87-92.

Chen, L., Gillenson, M.L., and Sherell, D.L., 2002. "Enticing Online Consumers: An Extended Technology Acceptance Perspective.” Information and Management, 39(8), 705-719.

Chismar, W.G., and Wiley-Patton, S., 2003. "Does The Extended Technology Acceptance Model Apply To Physicians?” Big Island, Hawaii Proceedings of the $36^{\text {th }}$ annual Hawaii International Conference on System Sciences (HICSS’03)(pp. 160-167).

Citrin, A.V., Sprott, D.E., Silverman, S.N., and Stem, D.E., 2000. "Adoption of Internet Shopping: The Role of Consumer Innovativeness.” Industrial Management and Data Systems, 100(7), 294-300.

Cooper, D.R., and Schindler, P.S., 2006. "Business Research Methods" (11 ${ }^{\text {th }}$ Ed.). New York, NY: McGraw-Hill.

Dabholkar, P.A., 1996. "Consumer Evaluations of New Technology-Based Self-Service Options: An Investigation of Alternative Models of Service Quality.” International 
Journal of Research in Marketing, 13(1), 29-51.

Davenport, T.H., and Prusak, L., 1998. "Working Knowledge: How Organization Manage What They Know." Harvard business School Press, Boston, MA.

Davis, F.D., 1989. "Perceived Usefulness, Perceived Ease of Use, and User Acceptance of Information Technology," MIS Quarterly, 13(3), 319-340.

Davis, F.D., Bagozzi, R.P., and Warshaw, P.R., 1989. "User Acceptance of Computer Technology: A Comparison of Two Theoretical Models,” Management Science. 35 (8), Pp.982-1003.

Garbarino, E., and Strahilevitz, M., 2004. "Gender Differences in the Perceived Risk of Buying Online and the Effects of Receiving: A Site Recommendation from a Friend." Journal of Business Research, 57(7), 768-776.

Gefen, D., and Straub, D.W., 1997. "Gender Differences in The Perception And Use Of E-Mail: An Extention to the Technology Acceptance Model,” MIS Quarterly, 389400.

Gerrard, P., and J.B. Cunningham, 2003. "The Impact of Perceived Risks on Banking Managers' Intention to Outsource Business Proccesses - A Study of the German Banking and Finance Industry." International Journal of Bank Marketing, 21(1), 1628.

Gunawardena, C.N., 1995. "Social Presence Theory and Implications for Interaction and Collaborative Learning in Computer Conferences." International Journal of Educational Telecommunications, 1(2/3), 147166.

Gunawardena, C.N., and Zittle, F.J., 1997. "Social Presence as a Predictor of Satisfaction within a Computer-Mediated Conferencing Environment." The American Journal of Distance Education, 11(3), 8-26.

Haythornthwaite, C., 1998. "A Social Network Study of the Growth of Community among Distance Learners.” Information Research, 4(1), http://informationr.net/ir/4-1/infres41. html, reaccesed: July 8, 2014.

Hislop, D., 2003. "Linking Human Resource Management and Knowledge Management via Commitment.” Employee Relations, 25(2), 182-202.

Holthouse, D., 1998. "Knowledge Research Issues.” California Management Review, 43(3), 277-280.

Hong, J.C., Hwang, M.Y., Hsu, H.F., Wong, W.T., and Chen, M.Y., 2011. "Applying the Technology Acceptance Model in a Study of the Factors Affecting Usage of the Taiwan Digital Archives System." Computers and Education, 57(3), 2086-2094.

Hsu, Meng-Hsiang., Ju, T.L., Yen, Chia-Hui., and Chang, Chung-Ming., 2007. "Knowledge Sharing Behavior in Virtual Communities: The Relationship between Trust, Self Efficacy, and Outcome Expectations.” International Journal of Human-Computer Studies, 65, 153-169.

Hung, Shiu-Wan., and Cheng, Min-Jhih, 2013. "Are You Ready For Knowledge Sharing? An Empirical Study of Virtual Communities.” Computer and Education, 62, 8-17.

Karahanna, E., Straub, D. W., and Chervany, N. L., 1999. "Information Technology Adoption Across Time: A Cross-Sectional Comparison of Pre-Adoption and PostAdoption Beliefs.” MIS Quarterly, 23(2), 183-213.

Lai, H.M., and Chen, C.P., 2011. "Factors Influencing Secondary School Teacher's Adoption of Teaching Blogs.” Computers and Education, 56(4), 948-960.

Lau, R.Y.K., 2012. “An Empirical Study of Online Social Netwoking for Enhancing University Students' Learning." International Journal of e-Education, e-Business, eManagement, e-Learning, 2(5), 425-448.

Lee, J.N., 2001. "The Impact of Knowledge Sharing, Organizational Capacity and Partnership Quality on IS Outsourcing Success.” Information and Management, 38, 323-335.

Liljander, V., Gillberg, F., Gummerus, J., and Riel, A.V., 2006. "Technology Readiness and the Evaluation and Adoption of SelfService Technologies.” Journal of Retailing and Consumer Services, 13(3), 177-191.

Lin, H., 2011. "An Empirical Investigation of Mobile Banking Adoption: The Effect of Innovation Attributes and KnowledgeBased Trust." International Journal of 
Information Management, Vol. 31, No. 3: 252-260.

Lin, HF., and Lee, G.G., 2006. "Effects of Socio-Technical Factors on Organizational Intention to Encourage Knowledge Sharing.” Management Decision, 44(1), 108-125.

Lin, K.M., 2011. "E-Learning Continuance Intention: Moderating Effects of User eLearning Experience." Computers and Education, 56(2), 515-526.

Lin, M.J.J., Hung, S.W., and Chen, C.J., 2009. "Fostering The Determinants of Knowledge Sharing in Professional Virtual Communities." Computers in Human Behavior, 25(4), 929-939.

Liu, Y., Li, H.X., and Carlsson, C., 2010. "Factors Driving the Adoption of $\mathrm{M}$ Learning: an Empirical Study.” Computers and Education, 55(3), 1211-1219.

Lowenthal, R.P., 2009. "The Evolution and Influence of Social Presence Theory on Online Learning.” Online Education and Adult Learning. Hersyey, PA: IGI Global.

Loyd, B.H. Gressard, C., 1984. "Reliability and Factorial Validity of Computer Attitude Scales.” Educational and Psychological Measurement. 44, 501-505.

Madden, M., and Lenhart, A., 2006. "Online Dating.” Retrieved from Pew Internet and American Life Project.

Midgley, D.F. and Dowling, G.R., 1978. "Innovativeness: The Concept and Its Measurement.” Journal of Consumer Research. 4, pp. 229-242.

Moore, G.C., and Benbasat, I., 1991. "Development of an Instrument to Measure the Perceptions of Adopting an Information Technology Innovation.” Information Systems Research, 2(3), 192-222.

Moore, M.G., and Kearsley, G., 2005. "Distance Education: A Systems View,” (2nd. Ed.). New York: Wadsworth.

Munger, C.F., and Loyd, B.H., 1989. "Gender and Attitudes towards Computers and Calculators: The Relationship to Math Performance.” Journal of Educational Computing Research, 5, pp.167-177.

Norman, D.A., 1998. "The Invisible Computer: Why Good Products Can Fail, The Personal
Computer Is So Complex, And Information Appliances are The Solution,” (1st. Ed.). Cambridge, London: MIT Press.

Parasuraman, A., 2000. Technology Readiness Index (TRI): "A Multipleitem Scale to Measure Readiness to Embrace New Technologies,” Journal of Service Research. 2 (4), pp. 307-320.

Parasuraman, A., and Colby, C., 1998. "A Scale for Measuring Customers' Technology Readiness: Replication, Refinement and Implications for Service Organizations.” Paper presented at the 1998 Frontiers in Services Conference, Nashville, TN.

Read, S. J., and Miller, L.C., 1995. "Stories Are Fundamental To Meaning and Memory: For Social Creatures, Could It Be Otherwise?” In R. S. Wyer (Ed.), "Knowledge and memory: The Real Story,” (pp. 139-152). Hillsday, NJ: Lawrence Erlbaum Associates.

Richardson, J.C., and Swan, K., 2003. "Examining Social Presence in Online Courses In Relation To Students' Perceived Learning and Satisfaction.” Journal of Asynchronous Learning Networks, 7(1), 6888.

Rodgers, E.M., 2003. "Diffusion of Innovations," ( $5^{\text {th }}$ ed.). New York: Free Press.

Rourke, L., Anderson, T., Garrison, D. R., and Archer, W., 2001. "Assessing Social Presence in Asynchronous Text-Based Computer Conferencing." Journal of Distance Education, 14.

Rovai, A.P., 2002. "Building a Sense of Community at a Distance.” International Review of Research in Open and Distance Learning, 3(1).

Ryu, S., Ho, S.H., and Han, I., 2003. "Knowledge Sharing Behavior of Physicians in Hospitals.” Expert Systems with Applications, 25,113-122.

Sánchez, R.A., and Hueros, A.D., 2010. "Motivational Factors That Influence the Acceptance of Moodle Using TAM." Computer in Human Behavior, 26(6), 16321640.

Scheier, M.F., and Carver, C.S., 1987. "Dispositional optimism, and physical wellbeing: the influence of generalized outcome 
expectancies on health.” Journal of Personality and Social Psychology, 55,169-210.

Senge, P., 1997. "Sharing Knowledge.” Executive Excellence, 14(11), 17-18.

Short, J., Williams, E., and Christie, B., 1976. "The Social Psychology of Telecommunications.” London: John Wiley and Sons.

Sun, H., and Zhang, P., 2003. "A New Perspective To Analyze User Technology Acceptance," Working Paper, Syracuse University.

Szajna, B., 1996. "Empirical Evaluation of the Revised Technology Acceptance Model." Management Science. (42:1), 85-92.

Taylor, S., and Todd, P.A., 1995. "Assesing IT Usage: The Role of Prior Experience.” MIS Quarterly. (15:1), 125-143.

Tsikriktsis, N., 2004. “A Technology ReadinessBased Taxonomy of Customers: A Replication and Extension.” Journal of Service Research, 7(1), 42-52.

Venkatesh, V., Morris, M.G., Davis, G.B., and Davis, F.D., 2003. "User Acceptance Of Information Technology: Toward A Unified View.” MIS Quarterly, 27(3), 425-478.
Vrasidas, C.C. and Glass, G.V., 2002. "A Conceptual Framework for Studying Distance Education," in C. Vrasidas and G.V. Glass (Eds.), "Distance education and distributed learning," (pp. 31-55). Greenwich, CT: Information Age Publishing.

Walther, J.B., and Parks, M.R., 2002. "Cues Filtered Out, Cues Filtered,” in M.L. Knapp and J.A. Daly (Eds.), "Handbook of interpersonal Communications,” 529-563. Thousand Oaks, CA: Sage.

Wasko, M.M. and Faraj, S., 2000. "It Is What One Does: Why People Participate and Help Others in Electronic Communities of Practice.” Journal of Strategic Information Systems, 9(2-3), 155-173.

Wijnhoven, F., 1998. "Knowledge Logistic In Business Contexts: Analyzing and Diagnosing Knowledge Sharing By Logistics Concepts.” Knowledge and Process Management, 5, 143-157.

Wu, I.L., and Chen, J.L., 2005. “An Extension of Trust and TAM Model with TPB in the Initial Adoption of On-Line Tax: an Empirical Study." International Journal of Human-Computer Studies, 62, 784-808. 